\author{
Asian Journal of Contemporary Education \\ $\operatorname{ISSN}(e): 2617-1252$ \\ DOI: $10.55493 / 5052 . v 6 i 1.4426$ \\ Vol. 6, No. 1, 44-53. \\ (C) 2022 AESS Publications. All Rights Reserved. \\ URL: www.aessweb.com
}

\title{
PERCEIVED ACADEMIC SOCIAL INFLUENCE FROM PARENTS, PEERS, AND TEACHERS ACROSS GENDER GROUPS: SCALE DEVELOPMENT
}

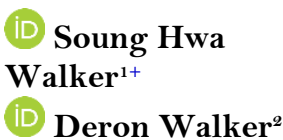

\author{
${ }^{2}$ School of Education, University of California, Riverside, United States. \\ Email:shkwalker18@gmail.com Tel:19518274633 \\ ${ }^{2}$ Modern Languages and Literature, California Baptist University, United \\ States. \\ Email:dwalker@calbaptist.edu Tel:19513434652
}

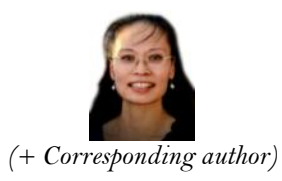

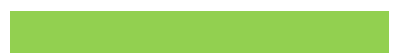

\section{Article History}

Received: 3 January 2021

Revised: 7 February 2022

Published: 25 February 2022

\section{Keywords}

Social influence Gender difference Factor analysis

Reliability

Validity.

\section{ABSTRACT}

This research examines psychometric properties of the 10-item Perceived Academic Social Influence Scale (PASIS) across gender groups with samples from Finland and Taiwan (Total $\mathrm{N}=4727,50.2 \%$ female adolescents). Results of composite scores, factor loadings, item-total correlations, and values of square root of Average Variance Extracted (AVE) confirmed strong reliability and validity of the scale. A Multi-Group Confirmatory Factor Analysis (MGCFA) revealed that measurement was equivalent at the level of scalar invariance across gender groups. Among three subcomponents of PASIS, latent mean score of teacher factor turned out to be higher than peer and parent factors regarding math achievement for female and male adolescents from both countries. Findings indicate that the PASIS is a reliable and valid measure to assess the perceptions of academic social influence for math learning, which can be utilized in different cultural contexts.

Contribution/ Originality: This study provides a sound survey tool to measure student perceptions regarding academic social influence from parents, peers, and teachers. Researchers, practitioners, and policy makers will find this 10-item PASIS is efficient and effective to administer to young children and adolescents across various educational settings.

\section{INTRODUCTION}

A social norm is one that is considered to influence one's behavior. The Theory of Reasoned Action (TRA) and Theory of Planned Behavior (TPB) have provided a sound theoretical basis for the relations between social norm and people’s behavior (Ajzen, 1991; Ajzen \& Fishbein, 1977). Nolan, Schultz, Cialdini, Goldstein, and Griskevicius (2008) have argued that normative social influence is potent and widespread -- witnessing the actions of other people has a powerful effect on behavior (p. 913). Empirical studies have found that adolescents' social norm from parents, friends, and teachers is strongly associated with academic behaviors regarding their math achievement (Lipnevich, MacCann, Krumm, Burrus, \& Roberts, 2011; Walker, 2017). A significant body of research also has pointed out that social norm influence or support from parents, peers, and teachers either directly or indirectly impacts student motivation, engagement, and outcomes (Ahmed, Minnaert, Van, \& Kuyper, 2010; Ansong, Okumu, Bowen, Walker, \& Eisensmith, 2017; Clark, Dorio, Eldridge, Malecki, \& Demaray, 2020; Lee \& Smith, 1999; Pan, Zaff, \& Donlan, 2017; Rosenfeld, Richman, \& Bowen, 2000; Walker, 2017; Wentzel, 1998). Additionally, research evidence indicates that social support strategy such as encouragement from friends or teachers plays a crucial role in increasing social connectedness 
(Hamm \& Faircloth, 2005) fostering psychological well-being of adolescents (e.g., self-efficacy and hope; Khan (2013)) and predicting academic achievement (Mu, Chen, \& Duan, 2021).

Although the importance of social influence on students' wellness and academic achievement is unequivocal, little research has investigated how female and male students perceive social norm influence from parents, peers, and teachers on their educational outcomes in an international context. Although numerous social support instruments exist, no empirical studies have examined validity and reliability of the perceived academic social influence measure across gender groups. Thus, we aimed to provide a multidimensional academic social influence scale and examine its measurement invariance across gender groups with a large national dataset from the 2012 Programme for International Student Assessment (PISA). In the following, we provide a brief background on social support scale development and its use on the recent empirical research, which led to the present investigation.

\subsection{Social Support Scale and its Impact on Educational Outcomes}

One of the most extensively used social support instruments is the Multidimensional Scale of Perceived Social Support (MSPSS), which consists of three subscales: family, friends, and significant others (Dahlem, Zimet, \& Walker, 1991; Zimet, Dahlem, Zimet, \& Farley, 1988). Although the 12-item MSPSS has been widely employed as a sound tool to measure social support in social sciences and health related research, it lacks applicability to measure academic social influence in relation to academic achievement, specifically. To supplement, a 60-item self-reported Child and Adolescent Social Support Scale (CASSS) was developed based on Tardy (1985) model of perceived emotional, appraisal, informational, and instrumental social support. The $1^{\text {st }}$ CASSS contains four groups with teachers, parents, close friends, and classmates (Malecki \& Elliott, 1999). The $2^{\text {nd }}$ CASSS includes five subcomponents with parents, teachers, close friends, classmates, and people in school (Kerres \& Kilpatrick, 2002). However, the 60-item CASSS has been considered too lengthy for young children and adolescents as they are known to be impatient or lack the necessary discipline to fully engage and complete the surveys in a meaningful way.

To address those concerns, scholars reduced survey items in order to efficiently administer social influence measures from parents, peers, and teachers. For example, Ahmed et al. (2010) utilized three different social support scales in their study - 5 items for the parental measure were used from Child and Adolescent Social Support Scale (Kerres \& Kilpatrick, 2002); 5 items measuring peer support were selected from the instrument of What is Happening In This Classroom (Fraser, McRobbie, \& Fisher, 1996); 5 items for the teacher support measure were adopted from the Classroom Life Measure (Johnson, Johnson, \& Anderson, 1983). The resulting 15-item measure showed reasonably good reliability scores (parent alpha $=0.70$, peer alpha $=0.66$, and teacher alpha $=0.74$ ). Examining the mediational roles of motivational beliefs and emotions between perceived social support and early adolescents' achievement, the authors found that the teacher support factor had "direct positive effects on competence, interest, importance and math enjoyment but a negative effect on math anxiety" (p., 42). But Ahmed et al. (2010) used only samples of $7^{\text {th }}$ grade from the Netherlands.

Another shorter version of social support scales can be found in the study of Ansong et al. (2017). The 6-item parental support scale, which referred to the extent of parents' involvement in their children's schooling, was utilized from the research of Ames, Khoju, and Watkins (1993). The 3-item classmate and teacher support scales, which measured the perception of support from classmates and teachers, were adapted from the study of Torsheim et al. (2012). Reported factor loadings from those reduced survey items showed good reliability and validity of the scale measure - the ranges of factor loadings for teacher subscale $=0.59$ to 0.97 ; classmate subscale $=0.48$ to 0.71 ; parent subscale $=0.56$ to 0.88 (Ansong et al., 2017). The authors found that the classmate support factor had a direct positive association with emotional engagement $(\beta=0.69, p=0.001)$ while the parental support factor had a direct positive association with behavioral engagement $(\beta=0.21, p=0.001)$. Although the teacher support factor did not have a direct effect on either behavioral or emotional engagement, the classmate support factor maintained a direct positive 
association with the teacher support factor $(\beta=0.44, p=0.001)$. Although this was a solid research study, the participants were limited to Ghanaian youths.

More recently, Clark et al. (2020) adopted 36 survey items from the 60-item CASSS instrument (Kerres \& Kilpatrick, 2002) for their investigation of the role of social support and grit on adolescents' academic achievement. The modified 36-item CASSS measure included parent, classmate, and teacher subscales. The shortened version of 36-item multidimensional social support measure had good reliability scores, alphas $=0.95,0.96$, and 0.96 , respectively. However, Clark et al. (2020) did not examine measurement of invariance as the participants of their study were limited to a single homogeneous adolescent group.

\subsection{Present Study}

In this study, we aimed to validate a 10-item multidimensional measure of Perceived Academic Social Influence Scale (PASIS) with samples from Finland and Taiwan by investigating psychometric characteristics, including factor structure, reliability, and validity. The PASIS includes parent, peer, and teacher subscales (See Figure 1), which could be easily utilized across heterogenous population samples. Concurrent validity was examined by the positive relationships between the PASIS and academic self-concept in math. We expected that each subscale of the PASIS would be positively correlated with math self-concept. Another important purpose of this study was to examine measurement invariance of the PASIS across gender groups from Finland and Taiwan. We also tested if measurement of the factorial structure of the PASIS (See Figure 1) would be equivalent across gender groups in an international context. Providing valid evidence of measurement invariance across group membership is considered a prerequisite for the latent mean comparison. When multidimensional components of a scale lack measurement invariance across different groups, study findings might mislead and interpretations of results might be biased (Horn \& McArdle, 1992; Schmitt \& Kuljanin, 2008; Widaman \& Reise, 1997; Yap et al., 2014).

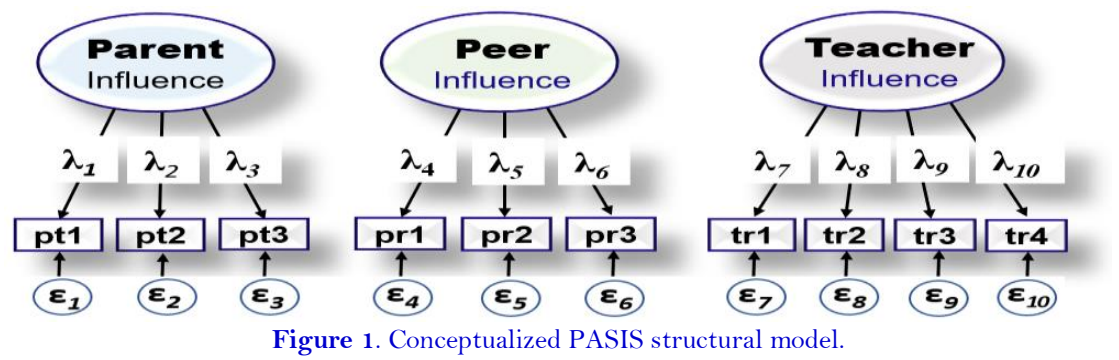

\section{METHODOLOGY}

\subsection{Data Source and Measures}

National samples from Finland and Taiwan for the 2012 PISA data (Total N $=4727,50.2 \%$ female adolescents) were included in the present investigation. Both Finland and Taiwan have been identified as high performing countries in math assessment but have rarely been studied closely for cross-cultural or cross-national comparison. From the Student Background Questionnaires (SBQ) of the 2012 PISA, 10-items were selected, which measured the perceived academic social influence related to math achievement: 3-item parent, 3-item peer, and 4-item teacher factors (See Table 1). Additionally, 4 items that represent the perceived math self-concept were selected in the study. Examples of math self-concept include: "I learn math quickly" and "In my math class, I understand even the most difficult work" (4-item math self-concept $\alpha=0.90$ ). All variables of SBQs in the present study were reported on a 4point Likert-type scale from 1 (strongly agree) to 4 (strongly disagree). However, all items were reverse-coded to avoid confusion, so that the higher numerical values represent stronger survey responses (i.e., $1=$ strongly disagree, $2=$ disagree, $3=$ agree, and $4=$ strongly agree). Reliability scores for parent, peer, and teacher factors were $\alpha=0.77$, $\alpha=0.72$, and $\alpha=0.86$, respectively. 


\subsection{Statistical Analyses}

To test if measurement of the factorial structure of the PASIS were invariant across gender from the two national samples, Multigroup Confirmatory Factor Analysis (MGCFA; (Joreskog, 1971; Kline, 2015)) was conducted with Mplus version 7 (Muthén \& Muthén, 1998). Known as a Structural Equation Modeling (SEM) software program, Mplus has been widely used for assessing measurement equivalence. Regarding factorial invariance testing, Widaman and Reise (1997) provided a sequence of four nested models to establish a best fitting model to data: Configural, Weak (also known as Metric), Strong (also known as Scalar), and Strict (also known as Residual/Uniqueness) invariance. Meanwhile, it has been argued that testing for Strict/Residual invariance is not necessary for comparing latent mean differences because the residuals are not part of the latent factor (Putnick \& Bornstein, 2016; Vandenberg \& Lance, 2000). Thus, the present study excluded the Strict invariance testing.

To assess model fit, insignificant Chi-Square $\left(\chi^{2}\right)$ results are desirable. Chi-Square $\left(\chi^{2}\right)$ testing is known to be sensitive to large samples, which tends to reject the null hypothesis (Marcoulides, Heck, \& Papanastasiou, 2005; Raykov \& Marcoulides, 2006; Walker, 2018) so that there is no discrepancy between the proposed model (i.e., the PASIS with three subscales) and the sample data from the 2012 PISA. Thus, the following incremental fit indices were used to evaluate model fit: (1) Comparative Fit Index (CFI; Bentler (1990)) (2) Root-Mean-Square Error of Approximation (RMSEA; Browne and Cudeck (1993)), and (3) Standardized-Root-Mean Square Residual (SRMR). According to the measurement literature, a reasonably good model fit shows that values of CFI are $>0.90$ along with the values of RMSEA and SRMR < 0.08 (Hu \& Bentler, 1999; Kline, 2015). Chen (2007) also suggested that $\Delta \mathrm{CFI}$ of less than 0.010, paired with $\triangle \mathrm{RMSEA}$ and $\triangle \mathrm{SRMR}$ of less than 0.015 would indicate an excellent model fit to the data (cited in Putnick and Bornstein (2016)).

Table 1. Descriptive statistics, item selectivity, and factor loading of the items.

\begin{tabular}{|c|c|c|c|c|}
\hline Items & Descriptions of the 2012 PISA SBQ & $\mathbf{M}(\mathbf{S D})$ & $\mathbf{r}_{\text {it }}$ & $\lambda(\mathbf{S E})$ \\
\hline \multicolumn{5}{|c|}{ Parent Norm Influence Factor } \\
\hline pt1 & My parents believe it's important for me to study math. & $3.20(0.68)$ & 0.66 & $0.83(0.007)$ \\
\hline $\mathrm{pt} 2$ & My parents believe that math is important for my career. & $3.00(0.75)$ & 0.65 & $0.81(0.007)$ \\
\hline pt3 & My parents like math. & $2.53(0.77)$ & 0.48 & $0.55(0.008)$ \\
\hline \multicolumn{5}{|c|}{ Peer Norm Influence Factor } \\
\hline pr 1 & Most of my friends do well in math. & $2.74(0.68)$ & 0.55 & $0.70(0.009)$ \\
\hline pre & Most of my friends work hard at math. & $2.69(0.69)$ & 0.61 & $0.80(0.008)$ \\
\hline pr3 & My friends enjoy taking math tests. & $2.04(0.73)$ & 0.47 & $0.55(0.009)$ \\
\hline \multicolumn{5}{|c|}{ Teacher Norm Influence Factor } \\
\hline $\operatorname{tr} 1$ & Teacher shows an interest in student's math learning. & $2.78(0.87)$ & 0.77 & $0.65(0.007)$ \\
\hline $\operatorname{tr} 2$ & Teacher gives extra math help when students need it. & $3.29(0.81)$ & 0.81 & $0.82(0.005)$ \\
\hline $\operatorname{tr} 3$ & Teacher helps students with their learning in math. & $3.40(0.76)$ & 0.78 & $0.87(0.004)$ \\
\hline $\operatorname{tr} 4$ & Teacher continues teaching until students understand. & $3.00(0.91)$ & 0.77 & $0.75(0.005)$ \\
\hline
\end{tabular}

\section{RESULTS}

\subsection{Preliminary Analyses}

Table 1 presents means, SDs, item-total correlations, and standardized factor loadings with SEs. CFA result yielded an excellent fit of the model to data: $\chi^{2}(32)=693.62, \mathrm{p}<0.001, \mathrm{CFI}=0.980$, RMSEA $=0.038(90 \% \mathrm{CI}$ : 0.035 - 0.040), and SRMR $=0.030$. All manifest variables (i.e., item indicators) were loaded significantly, $\lambda \geq 0.55, p$ $<0.001$. Moreover, item-total correlation scores indicate that the scale showed reasonably good to excellent item selectivities, $r_{\mathrm{it}} \geq 0.47$ (See Table 1). An item-total correlation test allows us to provide empirical evidence whether or not the item would measure the same construct with the rest of the items. Less than 0.30 might be a good sign that the corresponding item does not correlate well with the scale and, thus, may be considered to be eliminated (Field, 2018). 


\subsection{Reliability and Validity}

To assess internal consistency of the item indicators (manifested variables) of the PASIS measure, composite reliability (CR) was reported. All CR scores were $\geq 0.73$ (See Table 2), which indicates good reliability of the three facets of the PASIS (Hair, Sarstedt, Matthews, \& Ringle, 2016; Nunally, 1978; Wang, Wan, Huang, Huang, \& Kong, 2017). Estimated CR scores were obtained using the following formula (Fornell \& Larcker, 1981; Raykov, 1998):

$$
\begin{aligned}
C R & =\frac{\left(\sum \lambda_{i}\right)^{2}}{\left(\sum \lambda_{i}\right)^{2}+\left(\sum \varepsilon_{i}\right)} \\
\varepsilon & =1-\lambda_{i}^{2}
\end{aligned}
$$

Where $\lambda$ (Lambda) is the standardized factor loading for item $i$, $\varepsilon$ (Epsilon) is the error variance for item $i$. The error variance $(\varepsilon)$ is estimated based on the value of the loading $(\lambda)$.

Table 2. Composite score, AVEs, and correlation among the three subscales of the PASIS

\begin{tabular}{l|c|c|c|c|c}
\hline Factors & CR & AVE & $\mathbf{1}$ & $\mathbf{2}$ & \\
\hline 1. Parent & 0.78 & 0.55 & $(0.74)$ & \\
\hline 2. Peer & 0.73 & 0.48 & $0.26^{* *}$ & $(0.69)$ \\
\hline 3. Teacher & 0.86 & 0.58 & $0.17^{* *}$ & $0.23^{* *}$ & $(0.76)$ \\
\hline Math self-concept (MSC) & -- & -- & $0.25^{* *}$ & $0.11^{* *}$ & $0.18^{* *}$ \\
\hline $\begin{array}{l}\text { Note: Bolded values in diagonal with parenthes are the values of square root of AVEs. **p } 0.001 . \\
\text { CR and AVE for math self-concept were not reported since it is not a part of PASIS subscale. }\end{array}$
\end{tabular}

Construct validity was demonstrated via convergent and discriminant validity examination. The initial CFA result indicated that all factor loadings were $\geq 0.55$ (See Table 1) and the values of Average Variance Extracted (AVE) were $\geq 0.48$ (See Table 2), which confirms convergent validity (Fornell \& Larcker, 1981; Hair et al., 2016). AVE score was calculated with the sum of each squared factor loading $\left(\Sigma \lambda_{i}{ }^{2}\right)$ divided by the number of item indicators. Values of the square root of AVEs $(\geq 0.69)$ were higher than the inter-construct correlations $(0.17 \leq r \leq 0.26)$, which indicates strong evidence of discriminant validity (Fornell \& Larcker, 1981; Hair et al., 2016). Results also showed that each facet of the PASIS (parent, peer, and teacher subscales) is significantly positively correlated with math self-concept (MSC): correlation of parent factor with $\mathrm{MSC}=0.25$, peer factor with $\mathrm{MSC}=0.11$, and teacher factor with $\mathrm{MSC}=$ 0.18 , respectively.

\subsection{Measurement Invariance of the PASIS Factorial Structure across Gender}

Model 1 (Configural invariance) served as the baseline model, where all factor loadings were freely estimated. This baseline model was used to test if the factorial structure of the PASIS with three facets has the same pattern of free and fixed loadings for both samples of female and male students. Model 1 yielded an excellent fit, CFIs $\geq 0.977$ with SRMRs $\leq 0.040$ (See Table 3). Model 2 (Weak/Metric factorial invariance) was examined to see if each item was designated to the latent variable to a similar degree across gender by constraining all factor loadings. The result indicated that Model 2 was a great fit, CFIs $\geq 0.976$ with SRMRs $\leq 0.042$. No significant changes occurred when compared to Model 1, $\Delta$ CFIs $=-0.001$ with $\Delta$ SRMRs $=+0.002$ (see Table 3). Having attained Weak $/$ Metric invariance across gender groups indicates that the construct of the PASIS model components (i.e., parent, peer, and teacher factors) carried the same understanding for both female and male students from both countries. Model 3 (Strong/Scalar factorial invariance) was assessed for the equivalence of the item indicators (i.e., manifested variables) by constraining all item intercepts along with factor loadings across gender groups. Model 3 also fit well to the data, CFIs $\geq 0.969$ with SRMRs $\leq 0.044: \Delta$ CFIs $=-0.007$ and -0.008 with $\Delta$ SRMRs $=+0.002$ for all samples (See Table $3)$, which met the recommended criteria for establishing Strong/Scalar equivalence from the measurement invariance literature (See (Chen, 2007; Putnick \& Bornstein, 2016) for further details). Therefore, one can reasonably conclude that the meaning of the item indicators (manifested variables) was interpreted in almost the same way among female and male adolescents from Finland and Taiwan. 
Table 3. Fit indices for measurement invariance across gender.

\begin{tabular}{|c|c|c|c|c|c|c|}
\hline \multicolumn{7}{|c|}{ Entire Samples from Finland and Taiwan } \\
\hline Models & $\chi^{2}(d f)$ & CFI & RMSEA & SRMR & $\Delta \chi^{2}(d f)$ & $P$ \\
\hline M1 & $721.56(64)$ & 0.980 & 0.037 & 0.031 & $\overline{--}$ & $\overline{--}$ \\
\hline M2 & $750.42(71)$ & 0.980 & 0.036 & 0.032 & $28.86(7)^{\mathrm{a}}$ & $<0.001$ \\
\hline M3 & $999.88(78)$ & 0.973 & 0.040 & 0.034 & $249.46(7)^{\mathrm{b}}$ & $<0.001$ \\
\hline \multicolumn{7}{|c|}{ Finnish Samples } \\
\hline Models & $\chi^{2}(d f)$ & CFI & RMSEA & SRMR & $\Delta \chi^{2}(d f)$ & $P$ \\
\hline M1 & $501.10(64)$ & 0.977 & 0.040 & 0.030 & -- & -- \\
\hline $\mathrm{M} 2$ & $518.51(71)$ & 0.976 & 0.038 & 0.032 & $17.41(7)^{\mathrm{a}}$ & $<0.050$ \\
\hline M3 & $670.47(78)$ & 0.969 & 0.042 & 0.034 & $151.96(7)^{\mathrm{b}}$ & $<0.001$ \\
\hline \multicolumn{7}{|c|}{ Taiwanese Samples } \\
\hline Models & $\chi^{2}(d f)$ & CFI & RMSEA & SRMR & $\Delta \chi^{2}(d f)$ & $P$ \\
\hline M1 & $375.73(64)$ & 0.980 & 0.040 & 0.040 & -- & -- \\
\hline $\mathrm{M} 2$ & $394.01(71)$ & 0.979 & 0.039 & 0.042 & $18.28(7)^{\mathrm{a}}$ & $<0.050$ \\
\hline M3 & $521.76(78)$ & 0.971 & 0.043 & 0.044 & $127.75(7)^{\mathrm{b}}$ & $<0.001$ \\
\hline
\end{tabular}

Note: CFI= Comparative Fit Index; RMSEA = Root Mean Square Error of Approximation SRMR = Standardized Root Mean Square Residual.

$\mathrm{M} 1=$ Configural invariance model; M2 = Metric or Weak invariance model; M3 = Scalar or Strong invariance model.

$\Delta \chi^{2}(d f)^{\mathrm{a}}=$ model comparison for M2 vs. M1 and ${ }^{\mathrm{b}}=$ model comparison for M3 vs. M2

\subsection{Comparing Latent Mean of the PASIS across Gender}

Based on the establishment of the full Strong/Scalar invariance across gender, latent mean differences were examined. Sample size for the latent mean comparison contains no missing data on all variables. For example, a total of 3111 female students in Taiwan took the 2012 PISA math assessment, but 988 female students completed the background survey items regarding their perceptions of academic social norm influence or support from parents, peers, and teachers regarding their math learning.

As presented in Table 4, in both countries, parental norm influence subscale of the PASIS was rated higher for male students than females; $\mathrm{M}_{\text {Parent }}=2.93$ (male) and $\mathrm{M}_{\text {Parent }}=2.88$ (female) for Finland; $\mathrm{M}_{\text {Parent }}=2.66$ (male) and $\mathrm{M}_{\text {Parent }}$ $=2.56$ (female) for Taiwan. For the peer component of the PASIS, the mean score for male students was also higher than female students for Finland $\left(\mathrm{M}_{\text {Perr }}=2.44\right.$ and $\mathrm{M}_{\text {Per }}=2.36$, respectively), while no gender difference was found in Taiwanese samples. Regarding the teacher facet of the PASIS, the mean score from male students in Finland was higher than female students $\left(\mathrm{M}_{\text {Teacher }}=3.23\right.$ and $\mathrm{M}_{\text {Teacher }}=3.16$, respectively), while no statistically significant differences were reported on the mean scores for female $\left(\mathbf{M}_{\text {tacher }}=3.09\right)$ and male $\left(\mathbf{M}_{\text {tacher }}=3.07\right)$ adolescents in Taiwanese samples.

Table 4. Latent mean comparison by gender in both countries.

\begin{tabular}{|c|c|c|c|c|}
\hline & \multicolumn{2}{|c|}{ Finland } & \multicolumn{2}{|c|}{ Taiwan } \\
\hline & $\begin{array}{c}\text { Female } \\
(n=1384)\end{array}$ & $\begin{array}{c}\text { Male } \\
(n=1363)\end{array}$ & $\begin{array}{c}\text { Female } \\
(n=988)\end{array}$ & $\begin{array}{c}\text { Male } \\
(n=992) \\
\end{array}$ \\
\hline Parent & $2.88(0.59)$ & $2.93(0.58)$ & $2.56(0.61)$ & $2.66(0.61)$ \\
\hline Peer & $2.36(0.50)$ & $2.44(0.55)$ & $2.41(0.56)$ & $2.41(0.64)$ \\
\hline \multicolumn{5}{|c|}{ Independent Samples T-test and Cohen’s d: Female vs. Male } \\
\hline Factors & T-value & Cohen's d & T-value & Cohen's d \\
\hline Parent & $2.24 *$ & 0.09 & $2.55 * *$ & 0.11 \\
\hline Peer & $3.99^{* * * *}$ & 0.15 & $0.00(\mathrm{~ns})$ & 0.00 \\
\hline Teacher & $2.64^{* *}$ & 0.10 & $0.07(\mathrm{~ns})$ & 0.00 \\
\hline
\end{tabular}

Note: $\mathrm{M}=$ mean score, $\mathrm{SD}=$ standard deviation. ${ }^{*} p<0.05,{ }^{*} * p<0.01,{ }^{*} * * p<0.001 . \mathrm{ns}=$ statistically non-significant.

Cohen's $d$ is reported for the effect size difference: small (0.20), medium (0.50), and large (0.80).

Overall, the most outstanding finding of the latent mean comparison highlights that both female and male adolescents rated the perceived teacher norm influence factor as the most significant attribute of the PASIS subscales for their math learning in both countries. On a 4-Point Likert-type scale (i.e., $1=$ strongly disagree, $2=$ disagree, 3 $=$ agree, and $4=$ strongly agree), the teacher factor of PASIS ranged from 3.07 to 3.23 (See Table 4). 


\section{DISCUSSION, CONCLUSION, AND RECOMMENDATIONS}

The current research aimed to examine the reliability, validity, and measurement invariance of the multidimensional 10-item PASIS and compare latent mean differences across gender with national samples from Finland and Taiwan. To our knowledge, the present investigation is the first report of measurement invariance of the PASIS regarding math learning across gender groups in an international context. The results yielded strong psychometric properties for the PASIS: values of internal consistency reliability $(0.72 \leq \alpha \leq 0.76)$ and composite reliability scores $(0.73 \leq \mathrm{CR} \leq 0.86)$ were $\geq 0.70$. Factor loadings were $\geq 0.55$ and the values of AVE were $\geq 0.48$, which confirms reasonably good convergent validity (Hair et al., 2016). To meet the divergent validity requirement, it was evident that all values of the square root of AVEs were greater than inter-subscale correlations (See Table 2). Importantly, multi-group CFA demonstrated configural, weak/metric, strong/scalar invariance of the PASIS between female and male adolescents. Results also indicate that the structure of PASIS with parent, peer, and teacher subscales was applied well across gender groups within the two culturally distinctive countries, Finland and Taiwan. Based on the strong/scalar measurement invariance across gender groups, any mean differences between female and male students reflect true gender differences of their perceptions on parent, peer, and teacher factors, not due to different interpretations of the survey items. Moreover, results of the present investigation suggest that the PASIS is a reliable and valid measure to assess students' perceptions of academic social influence related to math learning in an internal context. Additionally, each subscale of the PASIS was significantly positively correlated with math selfconcept.

Regarding the gender differences of latent mean comparison for Taiwanese samples, male adolescents had higher rates than females for the parent social norm influence (but not for the peer or teacher norm influences) on their math learning. Although the gender difference (Cohen's d = 0.11) in parent factor may be considered small (see Table 4), this could be interpreted that parent(s) in Taiwan might stress importance of learning math to boys more than girls, or at least students perceive it that way. Meanwhile, concerning Finland samples, female students rated all three subcomponents of social norm influences lower than male students. The most significant lower rating from females was reported on the peer influence component. One possible explanation for these results could be that peer influence might play stronger for boys than girls among Finland adolescents regarding academic behaviors in learning math. Future studies might examine the underlying attributes of gender and cultural differences in math learning among other Asian and Western countries.

Another significant finding involves teacher differences. Female and male adolescents in both countries rated that the perceived teacher norm influence factor was the strongest attribute of the PASIS for their math learning. This finding is consistent with prior studies in terms of teacher care regarding math achievement (Lewis et al., 2012; Muller, 2001; Umarji, Dicke, Safavian, Karabenick, \& Eccles, 2021; Walker \& Walker, 2021). Given that Finland and Taiwan represent high achieving countries in math performance, future research might consider including other national samples from below the OECD average score to further confirm psychometric properties of the PASIS and whether or not the results would yield similar outcomes to the present investigation. Given that the teacher facet of the PASIS was the strongest perceived attribute for math learning for both female and male students within these two high achieving countries, the quality of teacher training programs should be continually valued and prioritized. Furthermore, as prior research has also indicated, more focus on teacher care should be promoted in terms of explicit instructional practices for math teaching and learning (Lewis et al., 2012; Muller, 2001; Umarji et al., 2021; Walker \& Walker, 2021).

\subsection{Limitations and Strengths}

All survey items of the PASIS were from the 2012 PISA Student Background Questionnaires (SBQs). In addition, the national samples we used from the 2012 PISA dataset were only Finland and Taiwan among 65 OECD participated countries. Thus, it is encouraged to interpret the results with caution. However, the present study's 
findings show strong evidence to confirm that the PASIS is a valid and reliable tool to measure the perceptions of academic social norm influence scale in math across gender, which could be utilized in other educational contexts.

Funding: This study received no specific financial support.

Competing Interests: The authors declare that they have no competing interests.

Authors' Contributions: Both authors contributed equally to the conception and design of the study.

\section{REFERENCES}

Ahmed, W., Minnaert, A., Van, D. W. G., \& Kuyper, H. (2010). Perceived social support and early adolescents' achievement: The mediational roles of motivational beliefs and emotions. Journal of Youth and Adolescence, 39(1), 36-46.Available at: https://doi.org/10.1007/s 10964-008-9367-7.

Ajzen, I. (1991). The theory of planned behavior. Organizational Behavior and Human Decision Processes, 50(2), $179-211$.

Ajzen, I., \& Fishbein, M. (1977). Attitude-behavior relations: A theoretical analysis and review of empirical research. Psychological Bulletin, 84(5), 888-918.

Ames, C., Khoju, M., \& Watkins, T. (1993). Parent involvement: The relationship between school-to-home communication and parents' perceptions and beliefs (Report No. 15). Urbana, IL: ERIC Document Service No. ED362271, Center on Families, Communities, Schools, and Children’s Learning, Illinois University.

Ansong, D., Okumu, M., Bowen, G. L., Walker, A. M., \& Eisensmith, S. R. (2017). The role of parent, classmate, and teacher support in student engagement: Evidence from Ghana. International Journal of Educational Development, 54, 5158.Available at: https://doi.org/10.1016/j.ijedudev.2017.03.010.

Bentler, P. M. (1990). Comparative fit indexes in structural models. Psychological Bulletin, 107, 238-246.Available at: https://doi.org/10.1037/0033-2909.107.2.238.

Browne, M. W., \& Cudeck, R. (1993). Alternative ways of assessing model fit. In K. A. Bollen \& J. S. Long (Eds.), Testing structural equation models (pp. 136-162). Newbury Park, CA: Sage.

Chen, F. F. (2007). Sensitivity of goodness of fit indexes to lack of measurement invariance. Structural Equation Modeling: $A$ Multidisciplinary Journal, 14(3), 464-504.Available at: https://doi.org/10.1080/10705510701301834.

Clark, K. N., Dorio, N. B., Eldridge, M. A., Malecki, C. K., \& Demaray, M. K. (2020). Adolescent academic achievement: A model of social support and grit. Psychology in the Schools, 57(2), 204-22 1.Available at: https://doi.org/10.1002/pits.22318.

Dahlem, N. W., Zimet, G. D., \& Walker, R. R. (1991). The multidimensional scale of perceived social support: A confirmation study. Journal of Clinical Psychology, 47(6), 756-761.

Field, A. (2018). Discovering statistics using SPSS (5th ed.). London: Sage Publications.

Fornell, C., \& Larcker, D. F. (1981). Evaluating structural equation models with unobservable variables and measurement error. Journal of Marketing Research, 8(1), 39-50.Available at: https://doi.org/10.2307/3151312.

Fraser, B. J., McRobbie, C. J., \& Fisher, D. L. (1996). Development, validation and use of personal and class forms of a new classroom environment instrument. Paper presented at the Annual Meeting of the American Educational Research Association, New York.

Hair, J. J. F., Sarstedt, M., Matthews, L. M., \& Ringle, C. M. (2016). Identifying and treating unobserved heterogeneity with FIMIX-PLS: Part I-method. European Business Review, 28(1), 63-76.

Hamm, J. V., \& Faircloth, B. S. (2005). The role of friendship in adolescents' sense of school belonging. Nerw Directions for Child and Adolescent Development, 2005(107), 61-78.

Horn, J. L., \& McArdle, J. J. (1992). A practical and theoretical guide to measurement invariance in aging research. Experimental Aging Research, 18(3), 117-144.Available at: https://doi.org/10.1080/03610739208253916.

Hu, L. T., \& Bentler, P. M. (1999). Cutoff criteria for fit indexes in covariance structure analysis: Conventional criteria versus new alternatives. Structural Equation Modeling: A Multidisciplinary Journal, 6(1), 1-55.Available at: https://doi.org/10.1080/10705519909540118. 
Johnson, D. W., Johnson, R., \& Anderson, D. (1983). Social interdependence and classroom climate. The Journal of Psychology, 114(1), 135-142.Available at: https://doi.org/10.1080/00223980.1983.9915406.

Joreskog, K. G. (1971). Simultaneous factor analysis in several populations. Psychometrika, 36, 409-426.Available at: https://doi.org/10.1007/BFo2291366.

Kerres, M. C., \& Kilpatrick, D. M. (2002). Measuring perceived social support: Development of the child and adolescent social support scale (CASSS). Psychology in the Schools, 39(1), 1-18.Available at: https://doi.org/10.1002/pits.10004.

Khan, A. (2013). Predictors of positive psychological strengths and subjective well-being among North Indian adolescents: Role of mentoring and educational encouragement. Social Indicators Research, 114, 1285-1293.Available at: http://doi.org/10.1007/s11205-012-0202-x.

Kline, R. B. (2015). Principles and practice of structural equation modeling. New York, USA: Guilford.

Lee, V. E., \& Smith, J. B. (1999). Social support and achievement for young adolescents in Chicago: The role of school academic press. American Educational Research Journal, 36(4), 907-945.Available at: https://doi.org/10.3102/00028312036004907.

Lewis, J. L., Ream, R. K., Bocian, K. M., Cardullo, R. A., Hammond, K. A., \& Fast, L. A. (2012). Con cariño: Teacher caring, math self-efficacy, and math achievement among Hispanic English learners. Teachers College Record, 114.(7), 1-42.Available at: https://doi.org/10.1177/016146811211400701.

Lipnevich, A. A., MacCann, C., Krumm, S., Burrus, J., \& Roberts, R. D. (2011). Mathematics attitudes and mathematics outcomes of US and Belarusian middle school students. Journal of Educational Psychology, 103(1), 105-118.

Malecki, C. K., \& Elliott, S. N. (1999). Adolescents' ratings of perceived social support and its importance: Validation of the student social support scale. Psychology in the Schools, 36(6), 473-483.

Marcoulides, G. A., Heck, R. H., \& Papanastasiou, C. (2005). Student perceptions of school culture and achievement: Testing the invariance of a model. International Journal of Educational Management, 19(2), 140-152.Available at: https://doi.org/10.1108/09513540510582435.

Mu, W., Chen, Z., \& Duan, W. (2021). An extended evaluation of academic encouragement scale for adolescents. Journal of Psychoeducational Assessment, 39(3), 332-345.Available at: https://doi.org/10.1177/0734282920977723.

Muller, C. (2001). The role of caring in the teacher-student relationship for at-risk students. Sociological Inquiry, 71(2), 241255.Available at: https://doi.org/10.1111/j.1475-682x.2001.tb01110.x.

Muthén, L. K., \& Muthén, B. O. (1998). Mplus user's guide (6th ed.). Los Angeles, CA: Muthén \& Muthén.

Nolan, J. M., Schultz, P. W., Cialdini, R. B., Goldstein, N. J., \& Griskevicius, V. (2008). Normative social influence is underdetected. Personality and Social Psychology Bulletin, 34(7), 913-923.Available at: https://doi.org/10.1177/0146167208316691.

Nunally, J. C. (1978). Psychometric theory (2nd ed.). New York: McGraw-Hill.

Pan, J., Zaff, J. F., \& Donlan, A. E. (2017). Social support and academic engagement among reconnected youth: Adverse life experiences as a moderator. Journal of Research on Adolescence, 27(4), 890-906.Available at: https://doi.org/10.1111/jora.12322.

Putnick, D. L., \& Bornstein, M. H. (2016). Measurement invariance conventions and reporting: The state of the art and future directions for psychological research. Developmental Review, 41, 71-90.Available at: https://doi.org/10.1016/j.dr.2016.06.004.

Raykov, T. (1998). Coefficient alpha and composite reliability with interrelated nonhomogeneous items. Applied Psychological Measurement, 22(4), 375-385.Available at: https://doi.org/10.1177/014662169802200407.

Raykov, T., \& Marcoulides, G. (2006). A first course in structural equation modeling (2nd ed.). Mahwah, NJ: Lawrence Erlbaum.

Rosenfeld, L. B., Richman, J. M., \& Bowen, G. L. (2000). Social support networks and school outcomes: The centrality of the teacher. Child and Adolescent Social Work Journal, 17(3), 205-226.

Schmitt, N., \& Kuljanin, G. (2008). Measurement invariance: Review of practice and implications. Human Resource Management Review, 18(4), 210-222.Available at: https://doi.org/10.1016/j.hrmr.2008.03.003.

Tardy, C. H. (1985). Social support measurement. American Journal of Community Psychology, 13(2), 187-202.Available at: https://doi.org/10.1007/BFo0905728. 
Torsheim, T., Samdal, O., Rasmussen, M., Freeman, J., Griebler, R., \& Dür, W. (2012). Cross-national measurement invariance of the teacher and classmate support scale. Social Indicators Research, 105(1), 145-160.Available at: https://doi.org/10.1007/s11205-010-9770-9.

Umarji, O., Dicke, A.-L., Safavian, N., Karabenick, S. A., \& Eccles, J. S. (2021). Teachers caring for students and students caring for math: The development of culturally and linguistically diverse adolescents' math motivation. Journal of School Psychology, 84, 32-48.Available at: https://doi.org/10.1016/j.jsp.2020.12.004.

Vandenberg, R. J., \& Lance, C. E. (2000). A review and synthesis of the measurement invariance literature: Suggestions, practices, and recommendations for organizational research. Organizational Research Methods, 3(1), 4-70.Available at: https://doi.org/10.1177/109442810031002.

Walker, S. H. (2017). Examining the effects of non-cognitive factors on mathematics achievement across national groups: USA, Germany, Japan, and Korea. Doctoral Dissertation, University of California, Riverside. ProQuest Dissertations Publishing (10287503).

Walker, S. H. (2018). Reliability, validity, and measurement invariance of attitudinal and social norm factors in math. Journal of Studies in Education, 8(3), 37-51.Available at: https://doi.org/10.5296/jse.v8i3.13340.

Walker, D., \& Walker, S. H. (2021). Empowering care in the inner-city: Meeting standards with high expectations. Educational Review, 73(3), 330-345.Available at: https://doi.org/10.1080/00131911.2019.1619519.

Wang, Y., Wan, Q., Huang, Z., Huang, L., \& Kong, F. (2017). Psychometric properties of multi-dimensional scale of perceived social support in Chinese parents of children with cerebral palsy. Frontiers in Psychology, 8, 2020-2025.Available at: https://doi.org/10.3389/fpsyg.2017.02020.

Wentzel, K. R. (1998). Social relationships and motivation in middle school: The role of parents, teachers, and peers. Journal of Educational Psychology, 90, 202-209.Available at: https://doi.org/10.1037/0022-0663.90.2.202.

Widaman, F., \& Reise, S. P. (1997). Exploring the measurement invariance of psychological instruments: Applications in the substance use domain. In K. J. Bryant, M. Windle, \& S. G. West (Eds.), The science of prevention: Methodological advances from alcohol and substance abuse research (pp. 281-324). Washington, DC: American Psychological Association.

Yap, S. C., Donnellan, M. B., Schwartz, S. J., Kim, S. Y., Castillo, L. G., Zamboanga, B. L., \& Vazsonyi, A. T. (2014). Investigating the structure and measurement invariance of the multigroup ethnic identity measure in a multiethnic sample of college students. Journal of Counseling Psychology, 61(3), 437-446.Available at: https://doi.org/10.1037/a0036253.

Zimet, G. D., Dahlem, N. W., Zimet, S. G., \& Farley, G. K. (1988). The multidimensional scale of perceived social support. Journal of Personality Assessment, 52(1), 30-41.Available at: http://doi.org/10.1207/s15327752jpa5201_2.

Views and opinions expressed in this article are the views and opinions of the author(s), Asian Journal of Contemporary Education shall not be responsible or answerable for any loss, damage or liability etc. caused in relation to/arising out of the use of the content. 